$\mathbb{T}$ periodica polytechnica

\author{
Transportation Engineering \\ $38 / 2(2010) 9398$ \\ doi: 10.3311/pp.tr.2010-2.06 \\ web: http://www.pp.bme.hu/tr \\ (c) Periodica Polytechnica 2010
}

RESEARCH ARTICLE

\section{Regular interval timetable in Hungary}

\author{
Viktor Borza / Zoltán Imre Horváth
}

Received 2009-09-03

\begin{abstract}
Public transport in the Central Eastern region of Europe currently faces a situation very similar to Western European experiences from the 1970s onwards. Yet this current "curse" can be considered as a "blessing" as we are now in a position to select, as a point of depart towards progress, the most suitable, tried and tested method from among a number of approaches.

A modern, intermodal timetable structure relies on three basic factors: the periodicity, the symmetry and the everywhere-toeverywhere connection system at the network nodes. In the first part, the paper presents the economic principles; afterwards it defines the role of these factors in an integrated timetable structure and presents the standard values for the parameters used in the united European timetable structure.
\end{abstract}

\section{Keywords}

economic public service $\cdot$ regular interval timetable

\section{Viktor Borza}

Passenger Transport Business Unit Marketing and Sales Department, Rail Capacity Allocation Office Ltd., H-1054 Budapest, Bajcsy-Zsilinszky út 48, Hungary

e-mail: borzav@vpe.hu

\section{Zoltán Imre Horváth}

Infrastructure Business Unit, MÁV Hungarian State Railways Co, H-1087 Budapest, Könyves K. Krt. 54-60, Hungary

e-mail: horvathzo@mav.hu
Why should we maintain any more expensive and less efficient system, instead of adopting a regular interval timetable in railway transportation?

\section{Introduction}

Early as in 1960s, most railway companies in Western Europe - due to the dramatic shift towards private car usage - had to face a formidable decrease in the passenger transport. The development of transport infrastructures concentrated on motorways while the rail network has remained more or less unchanged. As the number of cars increased and the motorways spread, public transport decreased or - in some places - even broke off. Due to the lack of competitive innovations and investments, most state railway companies were inert, not being able to cope with individual transport.

Some railway companies developed various solutions for this problem. However, these solutions required such expensive infrastructure and rolling stock investments, that not every country could afford them, even in Western Europe. Some others came up with the idea of a revolutionary new public transport system, which is based on a symmetric, regular interval timetable structure. The greatest advantage of the new system was that it was able to provide new, attractive passenger services, without requiring expensive investments.

\section{The problem - nothing new under the sun [1]}

Early as in 1970s, most railway companies in Western Europe - due to the dramatic shift towards private car usage - had to face formidable decrease in the passenger transport. The development of transport infrastructures concentrated on motorways while the rail network has remained more or less unchanged.

From the 1990s onwards a shift towards a position in harmony with the requirements of environmental protection and a more human approach towards meeting transport needs led to a revival of rail transport including modernization efforts. However this did not necessarily result in the elimination of basic structural problems, nor in a comprehensive rise in public transport quality, as some decision makers made spectacular infrastructure investments a priority, often without proper attendance to the "software" problems of structure and service. Thus (only) in 
a fair number of relations rail transport again became the most attractive alternative but this did not everywhere stop the decline of the entire railway network.

In Hungary the railway passenger transport now faces those problems, which have been already well-known in the west during the past two decades:

- A lack of competitiveness due to the general availability and flexibility of individual road transport, as well as cheap air transport

- Ageing infrastructure and rolling stock

- More or less constant decline in passenger numbers

- Increased corporate loss.

Within the more developed regions of Europe two major approaches dominated in the response given to a similar situation. Best results were achieved by the "Swiss Model" based on ITF 1 . but what we would call the "French Model" also brought about some distinctive economic and territorial progress, even though overall result was increasing public loss compensation.

\section{Approaches to solving the problems The French Model}

Main characteristics:

- Operating only "fully loaded" trains

- Preserving passengers by expensive rolling stock and infrastructure developments

- Preferential approach - market segmentation

- Using high speed networks (TGV)

- Procreating hyper-modern suburban system (RER).

This model is developed on the basis of simple business economics. The first and most important step is to improve financial efficiency, therefore service is only provided in case of a demand matching the capacity (demand steered service model). The real problem with this approach is that, due to its obvious commitment to cutting expenses it does not sufficiently accommodate neither the dominance of general expenses in rail transport, nor the basic asymmetry of demands typical in the entire public transport sector (Fig. 1).

Next to improving financial efficiency the French Model, even at its best, results in overall passenger losses due to excluding the passengers of services cancellation due to less than cost optimal demand, which means on a network level that passengers are lost who would have used one of the "full" trains on their way back or on their onward trip.

\footnotetext{
1 It stands for Integraler Taktfahrplan from the German language meaning Regular Interval Timetable, the meaning of a symmetrical regular-interval timetable. Also known as „Intelligent Timetable”, or „Clockface schedule”, or Integrierter Taktfahrplan.
}

This phenomenon was observed in Hungary when the MÁV radically cut back their services in the 2004/05 timetable in order to cut costs. This had led to $6.4 \%$ reduction in passenger numbers following the cut back of (train-km) output by $5.7 \%$. Such an extent the loss of passengers was more than expected [2].

As for the cost structure of the MÁV passenger transport, more than a third is the share of rail infrastructure and two fifths are paid for rolling stock. In 2005 they paid 3\% less track access fees and $4 \%$ less traction fees, next to a $2,4 \%$ increase in overhead costs (mainly due to greater idle times of personnel and rolling stock, next the losses of system standstill). Also consider that they did not only fail to decrease costs but they transferred also losses to the infrastructure and traction/maintenance branches of business [3].

In a current Hungarian setting even the most carefully prepared and executed reduction of train services will typically result in a loss of passengers, though one might suspect an improved efficiency resulting in a cut in costs to a greater extent than causing increased costs elsewhere. A further loss in the number of passengers is detrimental at the request of the EU transport policy and principles of sustainability. In the French Model, in order to gain passengers the attraction of those services which are maintained must be significantly increased by means of extremely costly development of infrastructure and rolling stock. The results:

- Rising passenger numbers in the preferred segments - partly to the detriment of traditional segments (cannibalization)

- Further decrease of the share of the entire rail transport within the sector

- Ever more costly railway systems next to an increasing measure of state budget commitments.

It is interesting to compare transalpine traffic in Switzerland and France (Fig.2) despite of the fact that the model called "French" here is no longer consistently applied on the French railway market, and naturally we meet such demand driven service models elsewhere. SNCF have adopted a regular interval timetable structure on some of their partial networks.

\section{The Swiss Model}

Main characteristics:

- Since 1982 a regular timetable designed to meet peak period demand is maintained all day and all week long.

- In 1982 to begin with, the Swiss had some of the oldest (but well maintained) rolling stock in Western Europe.

- Relatively low speed on main lines (80-140 km/h).

- Between 1982 and 92 only isolated infrastructure developments with minimal costs took place, geared to service needs in harmony with the timetable. 

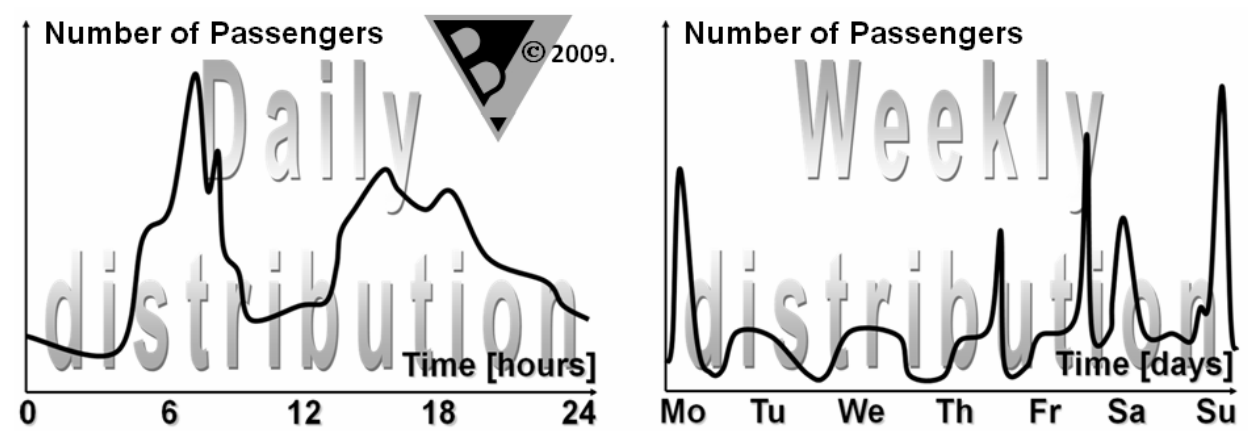

Fig. 1. Typical daily and weekly distribution of passengers (source: [2])

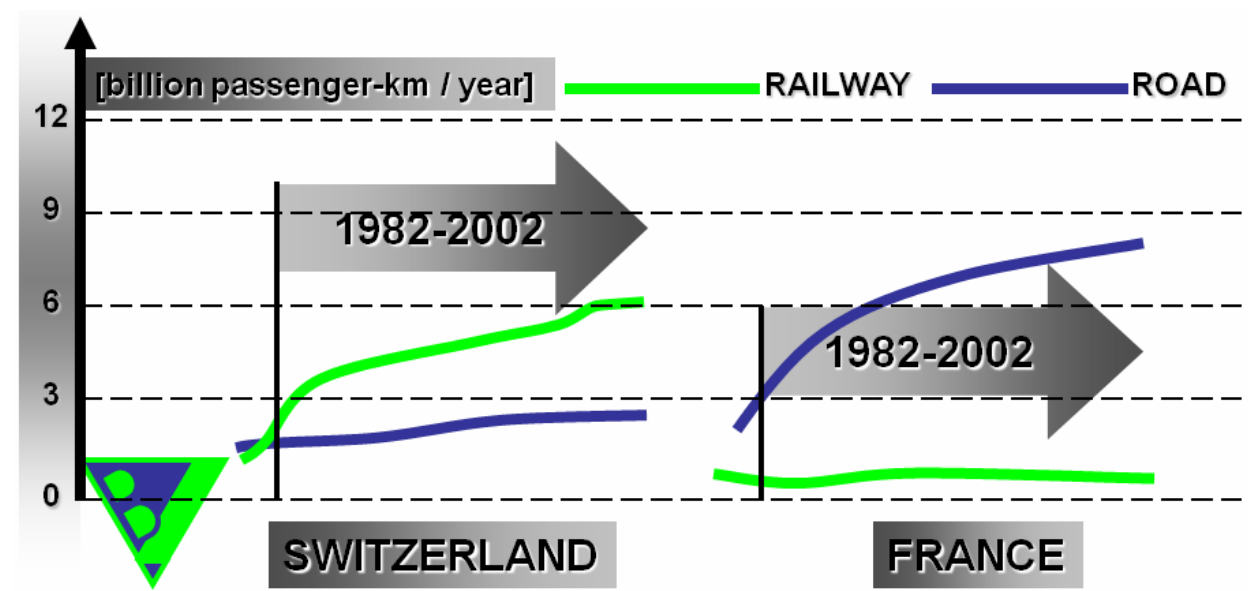

Fig. 2. Transalpine traffic (source: www.alptransit.ch)

- A national transport scheme with broad inter-modal cooperation based on the integral timetable which includes bus and city transports.

The supply driven service model applied in Switzerland takes into account the dominance of overhead in transport (rail in particular): "There is nothing more expensive than a standing train!" It is true that the supply driven performance (the amount of services performed by the given personnel and rolling stock) does not cause a significant cost rise, in Switzerland the available public transport capacity "runs to peak" most of the day resulting in a more flexible, attractive system able to serve as a true alternative to individual road transport. In a system with a regular interval timetable passengers are able to travel at least hourly between any two points of the system which - next to a symmetric timetable structure geared on quick changes of a few minutes - even without high-speed tracks creates a passenger friendly, highly available system. Besides the increase in performance and quality of service, other essential results are as follows [4]:

- The share of Swiss railways in the modal split is four times the European average.

- The entire public transport sector experienced dynamic passenger growth.

- Profitable rail passenger transport(!)

\section{Essential cost factors of rail passenger services}

The factors related to Regular Interval Timetable systems are:

1 track access fees (and other fees related to infrastructure)

2 traction fees (and other fees related to rolling stock)

3 depreciation and maintenance costs of rolling stock

4 personnel costs (related to passenger services)

5 real estate, accounting, corporate and administrative overhead 6 marketing costs.

The share of variable costs in Hungarian passenger rail transport was only the fortieth part of the entire cost (about 2,5\%). All the rest is practically independent of the level of performance. The budget of railway track infrastructure is more or less the same over the years (the randomly fluctuating cost differences are not driven by the performance level), costs can be covered by access fees and public cost compensation. Expenses must exactly match the incomes since infrastructure railway companies may not operate in a profit oriented manner. The aggregated value of incomes from track access fees remains pretty much the same independently of the performances of operators.

The global performance level is defined by the minimum public service level and the systems by and large face the same peaktime demand in France, Switzerland or Central Eastern Europe. If an operator intends to cut costs by running $10 \%$ less trains they might well face almost a $10 \%$ increase of specific track 
access fees the next years which are established based on the number of trains ordered for a given year.

Traction fees behave in a similar manner and even energy consumption does not strictly follow the level of actual performance. In fact overhead costs dominate in all major cost elements and due to this, given a capacity and a global performance, it is reasonable to "run to the peak" the rolling stock on all parts of a given network where an extra income can be achieved which at least matches the marginal costs.

\section{The principles [5]}

Let us see what this Regular Interval Timetable (ITF) is anyway? Not more but not even less than a standard, for organizing effectiveness of the transportation system. In this section, we will go through the most important rules and definitions needed to build up a modern ITF-system. The ITF relies on three main factors: the periodicity, the symmetry and the optimized connection-system at the network nodes.

\section{Periodicity}

First of all, let us see the explanation of the periodic timetable from the aspect of technology. In the case of a time interval $\mathrm{T}$ each adjacent $\mathrm{s}_{i}(\mathrm{t})$ and $\mathrm{s}_{j}(\mathrm{t})^{2}$ path-pairs of the same path type mask each other by shifting the same $\tau_{p}$ value, thus the paths are periodic. In formula:

$$
\frac{d \mathbf{s}_{i}(t)}{d t}=\frac{d \mathbf{s}_{j}(t)}{d t} ; t \in T ; \exists \tau_{p}, j, \forall i \Rightarrow \mathbf{s}_{i}(t)=\mathbf{s}_{j}\left(t \pm \tau_{p}\right)
$$

where $s(t)$ signs the train path on a distance time graph, T means the validity-term of period-structure and $\tau_{p}$ means the value of periodicity.

In the case if there is a homogeneous line (characterised by only one train path type), and the headway is identical between any arbitrary chosen adjacent path-pairs, the line has a periodic timetable, irrespectively of the value of periodicity. In this context, the value of $\tau_{p}$ could be as well 37 minutes, 24 hours or any other extremity.

The same principle can be applied to a line with heterogeneous train services, but there have to be equal $\tau_{p}$ for each train types.

\section{Symmetry}

Connections, travelling duration and station stopping times can be symmetrically built up for the outward and homeward journey of any connection. This means that if an optimal connection has been set up for the outward journey, the corresponding timetable slot can also be filled with a train path in the reverse direction, as a matter of principle.

This means that in the case of a symmetric system, we can find a symmetry-axis $t_{s}$ for each path-pair, which can be computed as the average of the departure time pairs at any station.

\footnotetext{
$2 i:=1$ to $n-1$ and $j:=2$ to $n$
}

In formula:

$$
\begin{array}{r}
\forall i \exists j ; \frac{d \mathbf{s}_{i}(t)}{d t}+\frac{d \mathbf{s}_{j}(t)}{d t} \equiv 0 \Leftrightarrow \\
\mathbf{s}_{i}(t+\tau)=\mathbf{s}_{j}(t-\tau)=t_{s}
\end{array}
$$

where $\mathrm{t}_{s}$ means the symmetry-axis and $\tau$ means the duration from/to the symmetry-axis, along the time axis.

When the complete daily timetable chart is symmetric to a common axis, there is the global symmetry-axis (typically at about early afternoon). Moreover, there can be several local symmetry-axes within every basic period.

\section{Spiders}

The optimal connections at interchange-stations are crucial for an ITF, since keeping the connection times low is the cheapest way to significantly reduce journey times. This requires that in a connecting terminal all trains meet always at the same time to enable the passengers to change between all lines. The name "spider" of such a sophisticated connection system comes from its typical graphical representation: if we plot the traffic diagram at an interchange-station, the diagram resembles the contours of a spider (Fig. ??).

In a station with interchange-spiders at every period, trains arrive and depart in the sequence of their gradient (signing its average travel speed) from/to each direction.

For example, before the "spider-time" the slowest (Regional) train-types arrive first, which are followed by InterRegio and InterCity trains (3).

\section{Direction A:}

$\frac{d \mathbf{s}(t)_{e a-R}}{d t} \leq \frac{d \mathbf{s}(t)_{e a-I C}}{d t} ; \max \left[s(t)_{e a-R}\right] \leq \max \left[s(t)_{e a-I C}\right]$

furthermore

$$
\begin{aligned}
& \frac{d \mathbf{s}(t)_{e a-I C}}{d t}+\frac{d \mathbf{s}(t)_{i a-I C}}{d t} \equiv 0 ; \\
& \mathbf{s}(t-\tau)_{e a-I C}=\mathbf{s}(t+\tau)_{i a-I C}=t_{x}
\end{aligned}
$$

where $t_{x}$ means the spider-time axis. Direction B and C are also similar as above.

It is obvious that at the interchange-station, periodicity of the $\mathrm{t}_{x}$ spider-time axis is $\tau_{r}$ or $\mathrm{n} \tau_{r}$, where $\mathrm{n}$ is an integer depending on the basic periodicity of the interconnected periodic schedules'.

In the case of a timetable which is not just periodic but shows symmetricity, the $t_{x}$ spider-time axis has a determinative position (5), which makes the planning of an ITF system easier.

$$
t_{x}=\left\{\begin{array}{l}
t_{s}+n \tau_{r} \\
t_{s} \pm \frac{\tau_{r}}{2}+n \tau_{r}
\end{array}\right.
$$

\section{ITF in Hungary: experiences and potential [6]}

The Hungarian ITF pilot project was established in 2004 in the Danube Bend region north of Budapest, a system of regional 


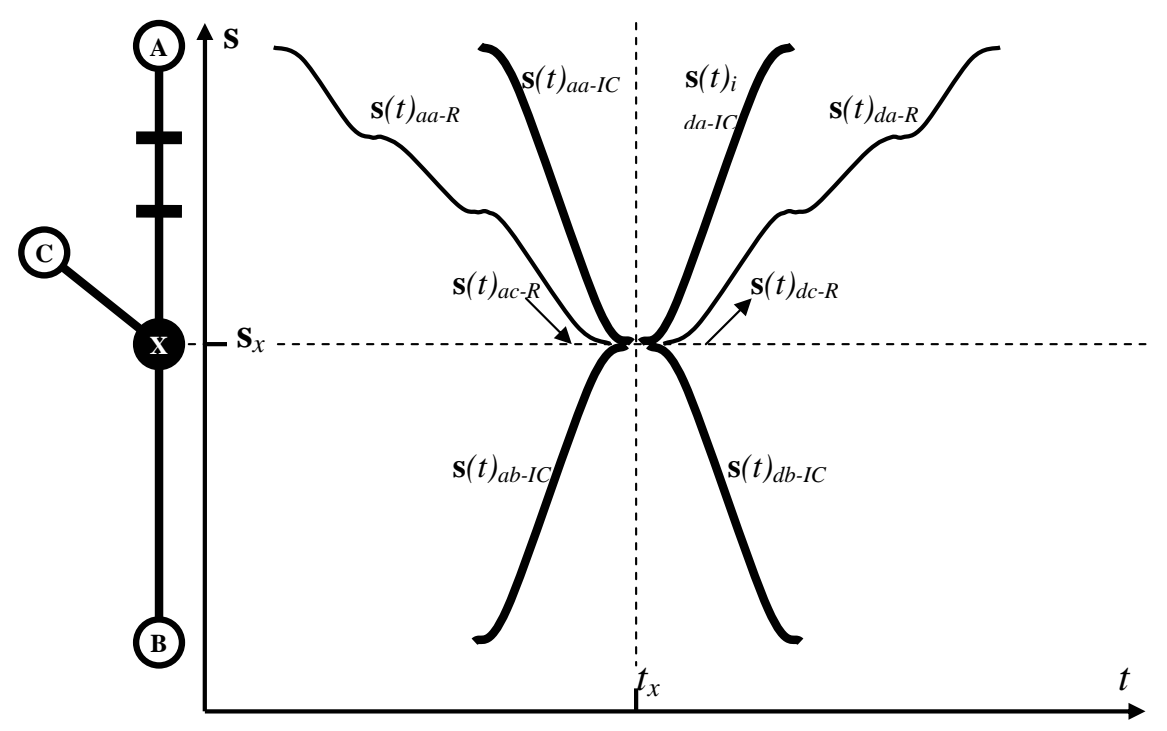

Fig. 3. Classic interchange-spider at a network-node (station $\mathrm{X}$ ) with arriving (index: a) and departing (index: d) trains from/to station A (index: a), station

and so-called zonal trains running according to a regular schedule. A $30 \%$ performance increase of the existing rolling stock was realized parallel to a cost increase measure of $0.4 \%$.

Due to the great success of the pilot project, in 2006 ITF system was for the north-eastern part of the country as a first step of extending a regular timetable to the entire country.

Tab. 1. First year results of railway passenger transport on MÁV network. During this year, there was a price rising (in 3 steps, together on average $30 \%$ rise). Source: [2]

\begin{tabular}{lcc}
\hline RESULTS & OTHER (NOT ITF) LINES & ITF LINES \\
\hline NUMBER OF PASSENGERS & $\mathbf{- 1 1 \%}$ & $\mathbf{- 2 \%}$ \\
\hline INCOME & $\mathbf{+ 1 5 \%}$ & $\mathbf{+ 3 1 \%}$ \\
\hline
\end{tabular}

The extension was planned for the whole network the next year, but unfortunately this step was adjourned due to political exigencies concerning restricting performance. During the year 2008 and 2009 it was allowed to organize ITF-mode on some more lines in the new timetable (as a part of the yearly timetable-change procedure), but the needed exhaustive reorganization (like in the north-eastern part of the network) is still waited for itself. The network's partly developed statement and other external and internal factors dimmed the positive effects of the Hungarian regular interval railway timetable, such as a severe rise in ticket prices, a lack of regional transport schemes and truly integral inter-modal timetables etc. Even so, summarized we found the prosperous way for the future by integrating our public transportation system by the rules of regular interval timetable in Hungary (Tab. 1).

Presently on a national network level contradictory tendencies prevail. While in the Danube Bend and in other areas a timetable with regular intervals is in force this has not been extended to the entire network and some hourly services e.g. in late morning were suspended because of the constraints of cost
B (index: b) or station C (index: c) as type InterCity (index: IC) or regional (index: R)

limitations which is still erroneous believed by some to be basically achieved by performance restraints. Meanwhile even the available poor statistical data clearly show the questionable results of several attempts concerning the performance cutbacks.

Summing up the aggregated performance function of costs and revenues in a manner true to measure we will get the business result (profit/loss) of the activity of passenger transport. Except for a few operators working with a regular integrated timetable passenger railway companies operate with losses throughout Europe, therefore it is reasonable first and above all to look at the performance function of business losses (Fig. 4).

At their present level of service a further performance reduction appears to threaten the very raison d'être of basic MÁV activities. The real possibility of overall loss reduction is to increase revenue by becoming attractive enough to acquire new potential passengers. The goal of a railway company operating in a rational manner should be to establish the point of minimal losses and attain it by reaching an optimal level of services. ITF if consequently applied as a useful method for operations appears to warrant such an optimum level of service, it allows operators to maintain a level where the value of marginal revenue is in excess of marginal cost.

If looking at the local potential of ITF, companies must take care of operating the regular interval timetable system in a reasonable way by considering the local infrastructure situation, as well as mentalities, traditions and organizational structures which are not always possible or appropriate to change. Nevertheless we put the questions which transport policy and corporate measures (legal and institutional background, integral tariff system) would be suitable and necessary in order to exert all the benefits of ITF in for achieving an optimal cost and size proportionality. 

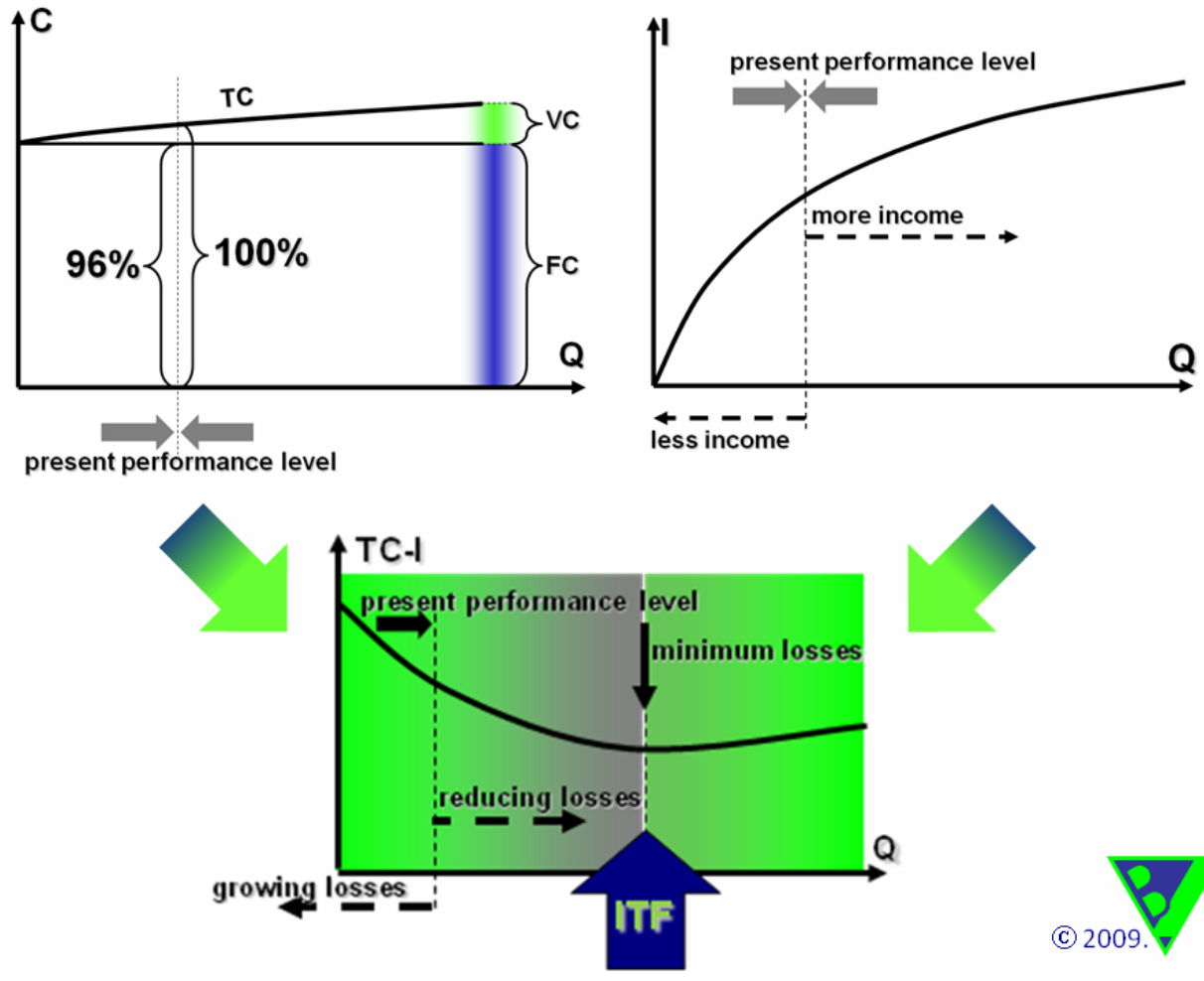

(C) 2009

Fig. 4. Total costs (TC) in railway transportation include mainly fix costs (FC) and a marginal part of various costs (VC) depending on the performance level. On the other side it is always much more difficult to find new passengers

\section{Conclusion}

The crisis situation typical for this region today was faced in Western Europe some 30 years back from here. From among the numerous approaches to cure the problems the Swiss Model appears to be the most effective, proving that ITF based operations give the only system for passenger railway companies to operate without losses.

Looking at the present macroeconomic performance levels of the regional states an important aspect of the Swiss Model is that with its help an almost immediate rise in the level of service can be attained without the need for costly investments. Based on Swiss (and partly, Hungarian) experience, within 1 to 7 years and next to a $4 \%$ cost increase, a 10 to $40 \%$ rise in revenues can be attained, improving the situation of companies afflicted by losses amounting to billions and that have to be compensated from time to time by the state budget. Therefore ITF, next to attaining a positive shift in the modal split, helps to decrease the external costs borne by society at large.

An ITF-based system of operations greatly contributes to creating a viable concept for efficient infrastructure development priorities. It also shows which possible development is not a priority. It clearly favours efficient human resources management (this area still makes up for $45 \%$ of the MÁV's cost structure) and due to its transparent, periodic nature the amount of planning work can be reduced to a fraction of the previous level, the remaining tasks not necessarily requiring in-depth railway related knowledge.

As the process of railway liberalization advances in line with (by increasing performance level) than loose them (by decreasing performance level). Aggregating costs and incomes (I) we could find the minimum point of deficit by developing an ITF system.

EU transport policy, track access for all operators without discrimination is a critical expectation, in view of which a general requirement is an objective set of rules based on related standards. A regular interval timetable is a viable setting for that.

In the case if the system can be extended to the entire network and the other branches of public transport would be integrated, based on experience it does not appear an audacious claim that within a decade rail passenger transport can be made a profitable business in Central Eastern Europe.

\section{References}

1 Borza V, Neumann I, How Passenger Transport could be Profitable (24 - 26 September 2009), 10-16. conference presentation - Railways in Transition. Eastern Europe Railways.

2 Incomes database of passenger transportation (, SZITA”); MÁV 2005.

3 Account of liabilities and assets; MÁV 2005.

4 Leu H P, Bahn2000 Project, Bratislava, 18 October 2005. conference presentation - Strategy of ŽSS,A.S. int he context of European Transport Policy.

5 Borza V, Kormányos L, Vincze B, Periodic timetable-map for Hungarian railway system by an adaptation of the European structure, (ŽEL 2004, Žilina, 2004, pp. 182-189.

$6 \_$, New regular interval timetables in operation on the suburban line of the Hungarian State Railways, (ŽEL 2005, Žilina, 2005, pp. 57-64. 